\title{
Herrn Prof. Dr. J. Meller zum 80. Geburtstag
}

Professor Meller begeht am 22. Oktober seinen 80. Geburtstag in voller Frische des Körpers und des Geistes. Aus diesem Anlaß ist es den Herausgebern und dem Yerlag der «Ophthalmologica» ein Bedürfnis, dem Jubilar ihre Glückwünsche darzubringen und den Dank dafür auszusprechen, daß er der «Zeitschrift für Augenheil-kunde» lange Jahre, von 1920-1938, seine Arbeitskraft, sein organisatorisches Talent und, man kann wohl ruhig sagen, seine $L \cdot$ iebe gewidmet hat. Von Band 44 ab war Meller Mitherausgeber der Zeitschrift für Augenheilkunde, von Band 49 ab hat er die Zeitschrift geleitet, zuerst mit Kuhnt, dann mit Behr und 1938 zu-sammen mit Bruckner und Weve, und ist dem Verlag Karger, mit dessen Inhabern, Vater und Sohn, er freundschaftlich verbunden war, immer mit seinem Rat und seiner ganzen Persönlichkeit zur Seite gestanden. Meller ist aus der Schule von Ernst Fuchs hervorgegangen und war der Liebhngsassistent seines großen Lehrers. Er war schon in seinen frühen Assistentenjahren ein ausgezeichneter Redner und sein Lehrtalent zog Studenten und Augenärzte aus aller Herren Ländern nach Wien. Er war ein glänzender Operateur. Zu seinen Operationskursen und Vorlesungen drängten sich in- und auslän-dische Ärzte. Für seine operative und seine Lehrbegabung zeugt

Ophthalmologica, Vol. 128, No. 4 (Oktober 1954)

\section{5}

202

Herrn Prof. Dr. J. Meller zum 80. Geburtstag

sein Buch «Die augenärztlichen Eingriffe», welches 6 Auflagen erlebt hat und ein Meisterwerk der klaren Darstellung und der Sprache ist, dem zwei englische Ausgaben vorausgingen.

Meller war Professor der Augenheilkunde in Innsbruck von 1915 bis 1918 und von da ab bis 1944 Vorstand der 1. Universitäts-Augenklinik in Wien, aus welcher Zeit seine wichtigsten wissen-schaftlichen Arbeiten stammen. In der Person Mellers besitzen wir die glückliche Verbindung von Histologen und Kliniker. Nur so konnten seine wichtigen Arbeiten über die Perineuritis und Peri-arteriitis ciliaris beim Herpes zoster uveae und über die Rolle des Ciliarepithels bei der Resorption von Glaskörperblutungen, seine Festlegung der Mitbeteiligung der Netzhaut und des Sehnerven bei der chronischen endogenen Iridocyclitis zustande kommen, nur so bekamen seine Arbeiten über die Histologie der Glaukomopera-tionen Blut und Leben. Seine bedeutendsten Arbeiten hat Meller auf dem Gebiete der sympathischen Ophthalmie und der Tuberkulose des Auges ver-í'aßt. Ihm gelang es nicht nur im Blute von Patienten, die an sym-pathischer Ophthalmie erkrankt waren, Tuberkelbazillen durch die Kultur, sondern auch Tuberkelbazillen im histologischen Schnitt von Augen mit sympathischer Ophthalmie nachzuweisen. 
Pillat, Wien.

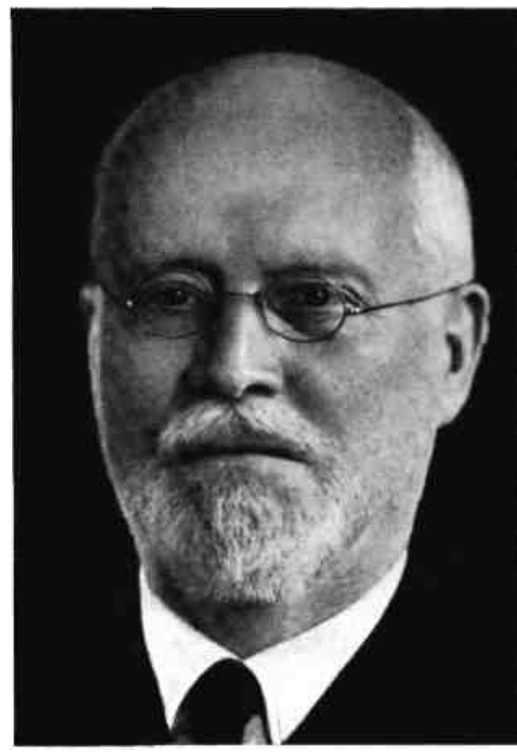

\section{Faches}

ein Stuck lebender Geschichte der Augenheilkunde. Aber er ist auch ein Mensch der sich in alien Lagen des Lebens selbst treu geblieben ist und der aufrecht und bescheiden durch seine Zeit geht

so be-scheiden

daß er

um alien Ehrungen in der Stadt seines Wirkens zu entgehen

seinen 80. Geburtstag fern von der Heimat verbrin-gen wird. So werden ihn denn unsere

Glückwünsche nur auf dem Wege über die «Ophthalmologica» erreichen. Die Herausgeber und die Mitarbeiter der Zeitschrift

der Verlag Karger sowie seine Freunde und Schüler entbieten ihm die herzlichsten Glückwünsche. 